\title{
Bird sky networks: How do avian scavengers use social information to find carrion?
}

\author{
Ainara Cortés-Avizanda,,${ }^{1,2,5}$ Roger Jovani,${ }^{3}$ José Antonio Donázar, ${ }^{2}$ and Volker Grimm ${ }^{1,4}$ \\ ${ }^{1}$ UFZ, Department of Ecological Modelling, Helmholtz Centre for Environmental Research-UFZ, Permoserstrasse 15, 04318 \\ Leipzig, Germany \\ ${ }^{2}$ Department of Conservation Biology, Estación Biológica de Doñana (CSIC), Americo Vespucio s/n, E-41092 Sevilla, Spain \\ ${ }^{3}$ Department of Evolutionary Ecology, Estación Biológica de Doñana (CSIC), Americo Vespucio s/n, E-41092 Sevilla, Spain \\ ${ }^{4}$ Institute for Biochemistry and Biology, University of Potsdam, Maulbeerallee 2, 14469 Potsdam, Germany
}

Abstract. The relative contribution of personal and social information to explain individual and collective behavior in different species and contexts is an open question in animal ecology. In particular, there is a major lack of studies combining theoretical and empirical approaches to test the relative relevance of different hypothesized individual behaviors to predict empirical collective patterns. We used an individual-based model to confront three hypotheses about the information transfer between social scavengers (Griffon Vultures, Gyps fulvus) when searching for carrion: (1) Vultures only use personal information during foraging ("nonsocial" hypothesis); (2) they create long chains of vultures by following both other vultures that are flying towards carcasses and vultures that are following other vultures that are flying towards carcasses ("chains of vultures" hypothesis); and (3) vultures are only attracted by other vultures that are sinking vertically to a carcass ("local enhancement" hypothesis). The chains of vultures hypothesis has been used in existing models, but never been confronted with field data. Testing is important, though, because these hypotheses could have different management implications. The model was parameterized to mimic the behavior and the densities of both Griffon Vultures and carcasses in a $10000-\mathrm{km}^{2}$ study area in northeastern Spain. We compared the number of vultures attending simulated carcasses with those attending 25 continuously monitored experimental carcasses in the field. Social hypotheses outperformed the nonsocial hypothesis. The chains of vultures hypothesis overestimated the number of vultures feeding on carcasses; the local enhancement hypothesis fitted closely to the empirical data. Supported by our results, we discuss mechanistic and adaptive considerations that reveal that local enhancement may be the key social mechanism behind collective foraging in this and likely other avian scavengers and/or social birds. It also highlights the current need for more studies confronting alternative models of key behaviors with empirical patterns in order to understand how collective behavior emerges in animal societies.

Key words: carrion resources; foraging; group-living; pulsed resources; sociality; Spain; vultures.

\section{INTRODUCTION}

The use of socially acquired (hereafter "social") information is increasingly recognized as a widespread phenomenon in biology, observed not only among highly social animals, but also in other taxa such as plants and bacteria. Social information influences animal movement, foraging, habitat selection, and mating (Galef and Giraldeau 2001, Giraldeau et al. 2002, Karban and Maron 2002, Valone and Templeton 2002). Social information is no less important for understanding the link between individual behavior

Manuscript received 26 March 2013; revised 12 August 2013; accepted 10 September 2013; final version received 18 December 2013. Corresponding Editor (ad hoc): L. M. Elbroch.

5 Present address: Theoretical Ecology and Biodiversity Change Group, Centro de Biologia Ambiental, Faculdade de Ciências da Universidade de Lisboa, 1749-016, Lisbon, Portugal. E-mail: cortesavizanda@gmail.com and population dynamics than personal information gathered by individuals directly interacting with the environment (also referred to as personal information; Danchin et al. 2004, Schmidt et al. 2010). This is particularly so for understanding collective animal behaviors. Theoretical approaches have shown that individual behavior based on simple and local social information could explain complex collective behaviors, such as bird flocking and fish schooling (Camazine et al. 2001, Hildenbrandt et al. 2010, Sumpter 2010), breeding synchrony (Jovani and Grimm 2008), or waves of collective vigilance (Beauchamp et al. 2012).

However, empirical work is still needed to describe which social information is used and how it is used in different real-world scenarios (Stamps et al. 2005). Moreover, what is needed, but rarely done (Taborsky 2008), is to combine theoretical and empirical approaches to compare the relative relevance of different hypotheses to predict natural patterns (Platt 1964, Grimm et al. 2005, 
Stamps et al. 2005; for flocking birds, see Hildenbrandt et al. 2010). Here, we studied an iconic example of the use of social information; how vultures find carrion resources and gather in large numbers to feed on carcasses within a short period of time (Tristam 1867, Houston 1974, Cortés-Avizanda 2010). We did so by modeling three hypotheses on the use of (social and private) information by foraging vultures and comparing the model outputs, corresponding to predictions of the two alternative hypotheses, with raw data on vultures attending sheep carcasses in the field.

Although opportunistic scavenging is widespread among vertebrates (De Vault et al. 2003), only vultures (with 23 extant species) are obligate carrion consumers. They have evolved morphological (e.g., beak shape), physiological (e.g., long fasting periods), and behavioral (e.g., soaring flight) specializations to find and feed on dead animals (Kruuk 1967, Houston 1974, Hertel 1994, Ruxton and Houston 2004). Carcasses are considered a resource that is often (1) difficult to locate both in space and time (i.e., appear in pulses; Ostfeld and Keesing 2000), (2) provides abundant food once encountered, but (3) is ephemeral due to intense intra- and interspecific competition with other bird scavengers, mammals, insects, and bacteria (DeVault et al. 2003, Burkepile et al. 2006). Carcasses can remain undiscovered for several hours or even days (see for example Donázar 1993, Cortés-Avizanda et al. 2012). Once detected, though, many vultures may gather within a short period of time (Cortés-Avizanda et al. 2012). Despite vultures being able to locate carcasses on their own (using personal information; Tristram 1867, Houston 1974, Mundy et al. 1992, Cortés-Avizanda 2010), it has been hypothesized that they widely use social information when foraging, thus potentially explaining this high synchrony of vulture arrival at carcasses. Specifically, it has been suggested that they use inadvertent social information, i.e., that vultures do not actively produce signals about carcass location, but that their flight behavior allows conspecifics to gain such information (Mundy et al. 1992). In this way, vultures are thought to create an informational transmission network in the sky that allows information about the discovery of a new carcass to spread fast (Tristram 1867, Houston 1974, Mundy et al. 1992).

While the use of social information by vultures is undisputed, the nature of this social information and how they use it remains an open question. Different theoretical studies have based models on the assumption that vultures create vulture chains while foraging ("chains of vultures" hypothesis). Such models have been used to explore the consequences of this foraging behavior for issues such as populations' viability (Jackson et al. 2008), the evolution of obligate scavenging (Dermody et al. 2011), and the impact of trophicresource management on vulture populations (Deygout et al. 2009, 2010). However, we argue that this presumed social behavior is not a well-established fact, but rather a hypothesis that needs to be contrasted with alternative hypotheses and confronted with data. The three competing hypotheses are:

(1) The "nonsocial" hypothesis that vultures only use personal information during foraging. That is, they search for carcasses by themselves, without relying on the behavior of conspecifics. Note that this behavior is also part of the other two hypotheses, because the first vulture to find the carcass will always do so by using personal information.

(2) The "local enhancement" (or area copying; Giraldeau et al. 2002) hypothesis, which focuses on the attraction of individuals from a distance to a certain site by the activity of conspecifics (Thorpe 1963, Danchin et al. 2004). In our case study, the trigger for this local enhancement was hypothesized to be the characteristic fast and direct descending flight of griffons after circling briefly over a carcass (Fischer 1969, Pennycuick 1972, Houston 1974, Mundy et al. 1992). This is a very conspicuous behavior with vultures sinking to the carcass at high speed (up to $144 \mathrm{~km} / \mathrm{h}$; Tucker 1988) from high altitudes above the ground (200-500 m; Tucker 1988). Thus, the local enhancement hypothesis states that vultures detect a carcass either by (1) seeing an unoccupied carcass by themselves, or by (2) seeing vultures feeding on a carcass. Moreover, they can be attracted to an area by (3) seeing a vulture descending in vertical flight to a carcass, eventually spotting the carcass or other vultures already feeding on it (CortésAvizanda et al. 2012).

(3) The "chains of vultures" hypothesis that can be traced back to 1867 when the Reverend Henry Tristram (Houston 1974: 169-170) speculated: "The process is probably this: The griffon-vulture, who first detects the quarry, descends from his elevation at once. Another, sweeping the horizon at a still greater distance, observes his neighbor's movements, and follows his course. A third, still farther removed, follows the flight of the second; he is traced by another, and thus a perpetual succession is kept up, so long as a morsel of flesh remains over which to consort." Thus, under this hypothesis, vultures discover the existence of carrion either by (1) seeing an unoccupied carcass by themselves, or by (2) seeing vultures feeding on a carcass. Moreover, (3) vultures can start following other vultures flying in direct (and gradually descending) flight towards a carcass. That means that when a vulture starts following another individual, it can also be followed by other vultures, triggering a social information cascade potentially leading vultures to create a chain of flying vultures eventually arriving to a carcass that they themselves had initially not seen. This hypothesis is implemented in recent modeling studies on vulture social foraging (Jackson et al. 2008, Deygout et al. 2009, 2010, Dermody et al. 2011).

Our aim was to test the power of these hypotheses to explain the foraging behavior of Griffon Vultures. The population consequences of individual social behaviors 
TABLE 1. The four possible states of Griffon Vultures (Gyps fulvus) in the model.

\begin{tabular}{ll}
\hline \hline Vulture state & \multicolumn{1}{c}{ Description } \\
\hline Searcher & a vulture without personal or social information about carcass location \\
Finder & a vulture that has seen either the carcass, feeders on a carcass, or finders sinking in vertical flight to a carcass \\
Follower & a vulture that is following other vultures (either finders or other followers) \\
Feeder & a finder that has already arrived at a carcass \\
\hline
\end{tabular}

are often nonlinear when performed by many individuals within a complex system (Camazine et al. 2001). This makes predicting the scaling-up from individual behaviors to population patterns by mere reasoning very difficult. We therefore built an individual-based model (Grimm and Railsback 2005) with three alternative submodels (one for each of the above hypotheses). The model was parameterized to mimic the behavior (visual acuity, foraging flight speed) and the densities of both Griffon Vultures (Gyps fulvus) and carcasses in the study area. Then, we confronted the predictions of the three alternative hypotheses obtained with the model with field data on the total number of Griffon Vultures arriving at each experimental carcass monitored in the field. To confront the model with data, we had to try and mimic a specific species in a specific region. Nevertheless, the model structure is generic and could easily be transferred to other avian scavengers and study areas.

\section{Methods}

\section{Study area and species}

The empirical study was performed in the Ebro Valley $\left(10000 \mathrm{~km}^{2}\right)$, northeastern Spain, which holds one of the most important European populations of avian scavengers (Del Moral and Martí 2001, Cortés-Avizanda et al. 2010, 2012, Donázar et al. 2010). Our focal species was the Griffon Vulture, a resident large soaring bird (mass of $10500 \mathrm{~g}$, wingspan of $2.6 \mathrm{~m}$ ). This species had a breeding population of $\sim 2400$ pairs $(\sim 11 \%$ of the Iberian population) in the study area and several hundred immature individuals. Griffon Vultures were the most abundant avian scavenger in the area and the only specialist avian scavenger (all other avian scavenger species make up a total of 500 breeding pairs; CortésAvizanda et al. 2010).

\section{Carcass monitoring}

From April to August 2004-2006, we monitored Griffon Vultures' use of carcasses of adult sheep (Ovis aries). We placed carcasses in open fields (i.e., fallow and pasture lands) throughout the study area, far from colonies, roosts, and vulture restaurants (Cortés-Avizanda et al. 2012) to avoid aggregations and contagious behavior that could be influencing the essential nature of the information transfer hypothesis. Sheep are the most common carcasses consumed by griffons in the study area due to extensive agro-grazing practices and the presence of farms in the area (Donázar et al. 2010).
Carcasses were placed $\sim 2 \mathrm{~h}$ after dawn and were monitored until they were completely consumed. Only carcasses on which vultures had fed were considered $(N$ $=25$ ). To avoid interfering with the birds' behavior, observations were made by two observers from a vehicle at a minimum distance of $300 \mathrm{~m}$. The total number of griffons attending each carcass was recorded. In all cases, once the first vulture landed at the carcass, it was quickly depleted within a day (Cortés-Avizanda et al. 2012).

\section{Model description}

A detailed model description following the ODD (overview, design concepts, details) protocol (Grimm and Railsback 2005, Grimm et al. 2006, 2010) can be found in the Appendix. The model was implemented in NetLogo version 5.0 (software freely downloadable from the NetLogo webpage; Wilensky 1999); the source code is given in the Supplement.

The model represented $N$ vul vultures searching for $N$ car carcasses in an area of $100 \times 100 \mathrm{~km}$. Boundaries were wrapped, leading to a torus geometry, to avoid edge effects. Vultures started as searchers and, depending on the submodel and their success at finding carcasses, they could become followers, finders, and eventually feeders (Table 1). In the three submodels (Fig. 1), carcasses started unoccupied (without feeders) and could become occupied (with feeders). Searchers and unoccupied carcasses were initially distributed at random in the lattice. One time step of the model corresponded to $10 \mathrm{~s}$; simulations lasted for $F_{\mathrm{h}}$ hours. The model was parameterized according to empirical information on vulture behavior, as well as the abundance of carcasses and foraging vultures in the study area (Table 2; Appendix).

Searchers flew at $F_{\mathrm{s}} \mathrm{km} / \mathrm{h}$, changing direction by $45^{\circ}$ (either right or left) every hour, on average (following Jackson et al. 2008). They detected unoccupied carcasses at a distance of $D_{\text {unocc }}$, becoming finders and flying directly, still at a constant speed $F_{\mathrm{s}} \mathrm{km} / \mathrm{h}$, towards the carcass until they arrived at the carcass, became feeders, and stopped moving for the rest of the simulation. This behavior was included in all three submodels, and constituted the whole nonsocial submodel. In a previous study, Deygout et al. (2010) modeled the flight of searching vultures as if they take into account the flight direction of other vultures, thus creating foraging groups. However, they found similar results between this model and a model assuming independent searching paths of individuals (as in our nonsocial model). Thus, 

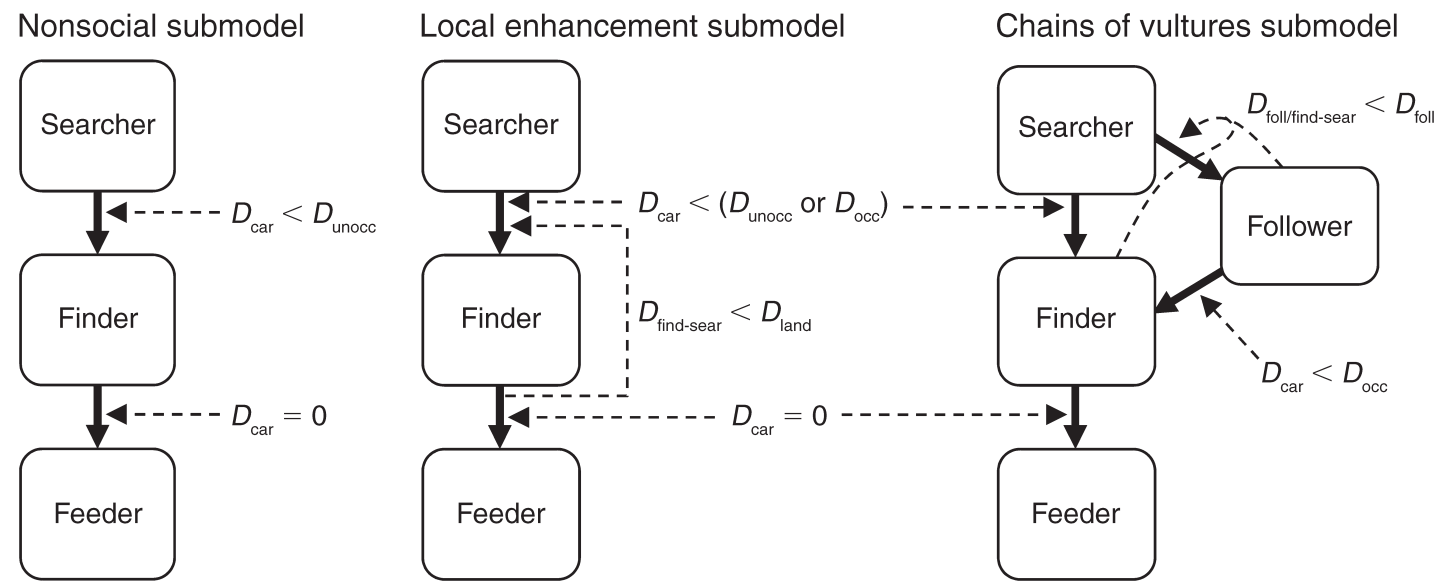

FIG. 1. Flow chart showing how Griffon Vultures (Gyps fulvus) change states in the different submodels. $D_{\text {car }}$ represents the linear distance of the vulture to the carcass, and $D_{\text {foll/find-sear }}$ represents the linear distance of a searcher to either a follower or a finder. See Tables 1 and 2 for clarification of the other terms and abbreviations. Solid lines show the transition between vulture states. Dashed lines show how vultures make other vultures change state. The dashed line departing from a solid line in the local enhancement submodel shows that finders make searchers become finders while in their transition from finder to feeder, i.e., in the very time step when they are descending to the carcass.

we did not explore this group-searching possibility further.

In the two social submodels, when a vulture arrived at the carcass, the carcass became visible to other vultures at the greater distance $D_{\text {occ }}$ (i.e., $D_{\text {occ }}>D_{\text {unocc; }}$ Table 2). Under the local enhancement submodel, searchers detected up to a distance of $D_{\text {land }}$ the vertical sinking behavior of finders arriving at a carcass, i.e., just before finders became feeders. Under the chain of vultures submodel, however, searchers detected finders and followers at the distance $D_{\text {foll }}$ and became followers, which could be subsequently seen by other searchers (at $\left.D_{\text {foll }}\right)$, creating a chain of vultures.

Note that $D_{\text {land }}=D_{\text {foll }}($ Table 2$)$, so the two social submodels only differed in their assumptions about how individuals used social information, not about over what distances vultures could gather such information. The chains of vultures could easily lead to an information cascade through the vulture network in the sky, with long chains of vultures flying towards a carcass that they had not seen directly. A similar, but spatially and temporally much more restricted, self-maintained, and dynamic positive feedback could occur in the local enhancement submodel, where searchers detect finders sinking at carcasses, then becoming finders themselves, and eventually signaling the carcass location to other searchers at the time they descend to the carcass.

The model was run 1000 times for each submodel using the default parametrization (Table 2), and the total number of vultures that arrived at each carcass was quantified at the end of each simulation.

\section{Uncertainty analysis}

Data and observations used for parameterization were partially incomplete or uncertain (Appendix). Moreover, different parameters were expected to interact in complex ways affecting the model output. We thus explored the robustness of the model output and, in

TABLE 2. Model parameters, their meaning, default values, and values used for the uncertainty analysis (UA).

\begin{tabular}{|c|c|c|c|c|}
\hline Parameter & Description & Submodel & Default & Values for UA \\
\hline$N_{\text {car }}$ & number of carcasses & $\mathrm{N}, \mathrm{L}, \mathrm{C}$ & 30 & $\mathrm{~N} \sim(30,5)[17,43]$ \\
\hline$N_{\text {vul }}$ & number of vultures & $\mathrm{N}, \mathrm{L}, \mathrm{C}$ & 2000 & $\mathrm{~N} \sim(2000,100)[1742,2258]$ \\
\hline$D_{\text {unocc }}$ & distance at which a searcher detects an unoccupied carcass & $\mathrm{N}, \mathrm{L}, \mathrm{C}$ & $300 \mathrm{~m}$ & $\mathrm{~N} \sim(300,50)[171,429]$ \\
\hline$D_{\text {occ }}$ & $\begin{array}{l}\text { distance at which a vulture (a searcher or a follower) } \\
\text { detects an occupied carcass }\end{array}$ & $\mathrm{L}, \mathrm{C}$ & $4 \mathrm{~km}$ & $\mathrm{~N} \sim(4,0.5)[2.71,5.29]$ \\
\hline$D_{\text {land }}$ & $\begin{array}{l}\text { distance at which a searcher detects a finder sinking in } \\
\text { vertical flight to a carcass }\end{array}$ & $\mathrm{L}$ & $7 \mathrm{~km}$ & $\mathrm{~N} \sim(7,0.875)[4.74,9.26]$ \\
\hline$D_{\text {foll }}$ & $\begin{array}{l}\text { distance at which a searcher detects a finder or a follower } \\
\text { going towards a carcass }\end{array}$ & $\mathrm{C}$ & $7 \mathrm{~km}$ & $\mathrm{~N} \sim(7,0.875)[4.74,9.26]$ \\
\hline$F_{\mathrm{h}}$ & number of foraging hours (one simulation) & $\mathrm{N}, \mathrm{L}, \mathrm{C}$ & $5 \mathrm{~h}$ & $\mathrm{~N} \sim(5,1)[2.43,7.58]$ \\
\hline$F_{\mathrm{s}}$ & flight speed of vultures & $\mathrm{N}, \mathrm{L}, \mathrm{C}$ & $45 \mathrm{~km} / \mathrm{h}$ & $\mathrm{N} \sim(45,5)[32.1,57.9]$ \\
\hline
\end{tabular}

Notes: Submodel "N" stands for the nonsocial submodel; "L" for the local enhancement submodel; and "C" for the chains of vultures submodel. "Values for UA" show the normal distribution, $\mathrm{N} \sim(\mu, \mathrm{s})$, from which pseudorandom values where extracted for the UA. Values in square brackets depict, for illustrative purposes, the range of values within which $99 \%$ of the simulated values in the UA fall (i.e., $\mu \pm 2.58 \sigma$ ). 


\section{Nonsocial submodel}

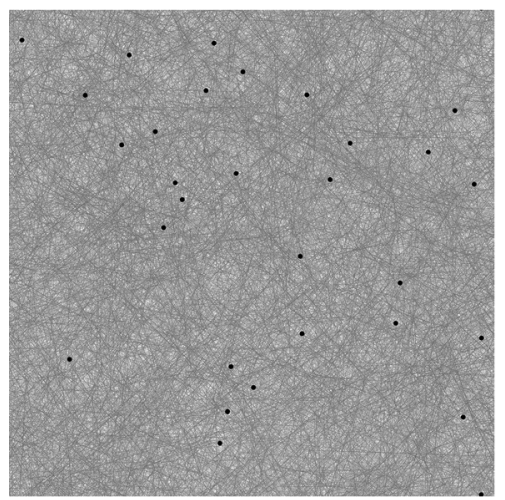

Local enhancement submodel

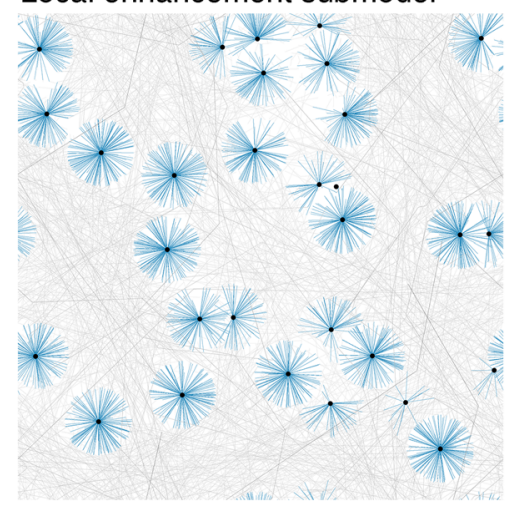

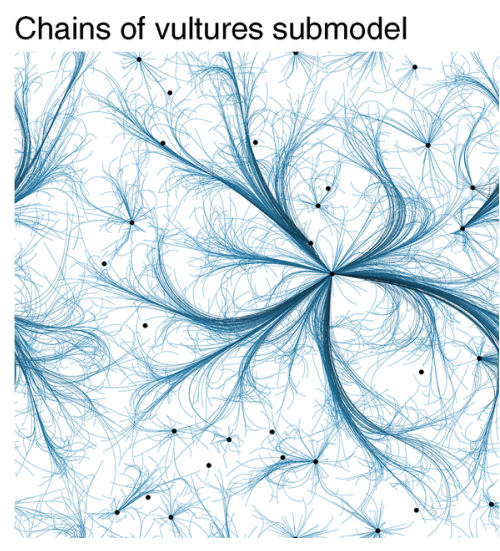

FIG. 2. Trajectories of vultures according to the three alternative searching submodels, shown at the end of a simulation run, using default parameters (Table 2). Carcasses are shown as black dots. Flight paths of searchers are in gray; flight paths of vultures once they turned to finders or followers are in blue. Note that most vultures entering the detection radius of a carcass in the local enhancement submodel run have been spread over the entire area, just as for the chain of vultures model.

particular, relative differences between the three submodels by performing an uncertainty analysis (Railsback and Grimm 2012). To do so, we ran each submodel 1000 times, with parameters for each run drawn randomly from certain ranges (see Table 2 and the Appendix for details).

In our default parameter set, we used values for total flight time, $F_{\mathrm{h}}$, and speed, $F_{\mathrm{s}}$, following Jackson et al. (2008) (see the Appendix for a detailed justification). To be able to directly compare our implementation of the Jackson et al. (2008) model (chain of vulture submodel), we also ran simulations with parameter values chosen by Jackson et al. (2008), i.e., $F_{\mathrm{h}}=3 \mathrm{~h}, F_{\mathrm{s}}=33 \mathrm{~km} / \mathrm{h}$, maintaining the other default values for the other parameters (Table 2). Since Jackson et al. (2008) parameterized $D_{\text {foll }}$ as either $4 \mathrm{~km}$ or $10 \mathrm{~km}$ in different model runs, we used a default value of $7 \mathrm{~km}$ for comparison, being the mean between these two extremes.

\section{RESULTS}

\section{Model output (default parameterization)}

The three submodels differed greatly in the spatial behavior of vultures (Fig. 2). Particularly striking were the chains of followers created in the chains of vultures submodel, with vultures arriving at carcasses from far away (Fig. 2). As a result, the three submodels differed greatly in the way feeders distributed across carcasses (Fig. 3). The chains of vultures submodel showed the highest dispersion of values with a highly right-skewed histogram (i.e., a small number of carcasses attracted most of the feeders; Fig. 3). The minimum, median, mean, and the maximum number of feeders that arrived at a single carcass in each of the 1000 simulations also differed between submodels (Fig. 4). For instance, in the nonsocial submodel, a single carcass never attracted more than 58 feeders, while up to 246 gathered under the local enhancement, and 2290 in the chains of vultures submodels (Fig. 4).

\section{Model output vs. empirical data}

Here we confronted output from model simulations (hypotheses predictions) with real data obtained in the field by monitoring the experimental carcasses. The shape of the frequency distribution of the number of feeders per carcass (Fig. 3) differed between real and simulated carcasses under the nonsocial and the chains of vultures submodels, but closely matched the histogram of the number of feeders predicted by the local enhancement hypothesis (Fig. 3).

We also analyzed the minimum, mean, median, and maximum number of feeders on a single carcass recorded in each of 1000 simulations for each submodel (Fig. 4). All three submodels slightly underestimated the minimum number of vultures found on experimental carcasses (particularly so in the chains of vultures submodel). The median was slightly overestimated $(+23.6 \%)$ by the local enhancement submodel, but was strongly underestimated by the nonsocial $(-63.2 \%)$ and the chains of vultures submodels $(-40.2 \%)$. The local enhancement submodel clearly outperformed the other two submodels on the mean and the maximum number of feeders, with a very close fit between empirical and simulated values.

\section{Uncertainty analysis}

Despite the variation in the model output caused by randomly drawing parameters from their ranges, the output of all three submodels was very consistent with that of the default parameterization (Appendix: Figs. A1 and A2). In particular, the relative differences between submodels remained essentially the same (compare Figs. 3 and 4 with Appendix: Figs. A1 and A2, respectively). Moreover, simulations using the parameterization suggested by Jackson et al. (2008) yielded the same conclusions (Appendix: Figs. A3 and A4). Therefore, 


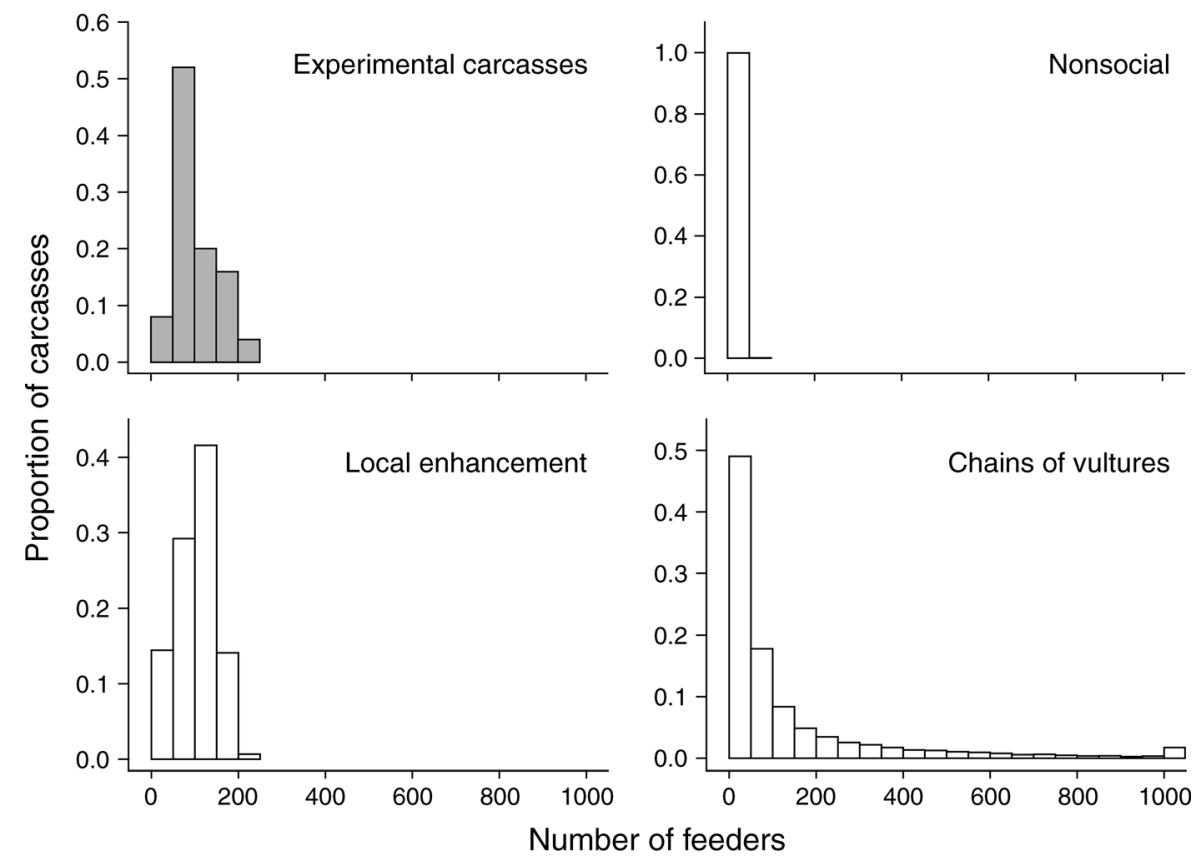

FIG. 3. Histograms of the number of feeders in each experimental (fieldwork data; gray bars) and simulated carcasses after 1000 model runs for each submodel (default parameterization; open bars; Table 2). In the chains of vultures histogram, carcasses with $>1000$ feeders are grouped in the last bar (values from 1001 to 2290).

the differences between submodels, and the conclusions drawn from the comparison between model outputs and empirical data, were robust regarding uncertainty in parameter values.

\section{DisCUSSION}

We used a simple individual-based model with three submodels (hypotheses) to understand how vultures use personal and social information to find carcasses. We found that hypotheses based on the use of social information outperformed the nonsocial hypothesis when confronted with field observations. This confirms the old idea that vultures use some sort of social information when foraging, which leads to the spectacular vulture gatherings around carcasses. The two social hypotheses modeled differed strikingly in their predictions, showing that the details of how vultures use social information (and which kind of information) are key to understanding how they find carcasses.

Recent modeling approaches on vulture foraging have been based on the chains of vultures hypothesis when attempting to forecast the consequences of different ecological scenarios (e.g., carcass availability) for vulture population dynamics. However, our study based on testing alternative models with empirical data favored the local enhancement hypothesis.

\section{Causal mechanisms}

Our modeling approach combined with field data suggests rejecting the chains of vultures hypothesis, at least for our study area. The chains of vultures hypothesis is based on the assumption that the vultures start flying towards the carcass not only when they see the carcass by themselves, but also when they see another vulture flying towards a carcass, thus creating an informational cascade. However, the details of how searching vultures could tell whether other vultures, which are several kilometers away, are searching as well, or are following a finder, or even are following only a follower, remain highly speculative. The chain of vultures hypothesis is based on the idea that "Once one bird sees a source of food its flight path changes from a slow, wandering flight into a direct dive towards the food. The rapid, direct flight path is very conspicuous and neighboring birds within sight also start to descend in the direction the first bird is heading, although they themselves may not be able to see the food. Vultures out of sight of the first bird, but within sight of the followers, also notice the change in flight behavior and start to follow, and so a chain reaction radiates out from the food site." (Houston 1974: 68). The same author and colleagues recently modeled this hypothesis (Jackson et al. 2008). In a later paper from the same team (Dermody et al. 2011: 1), it is explained, by citing Tucker (1988), how vultures are thought to know that they are following a reliable vulture chain (a chain that will go to a carcass): "When a vulture discovers a carcass it drops its feet, which increases drag and causes the bird to descend (Tucker 1988)." However, Tucker (1988) only reported that "The birds [White-backed Vultures, Gyps africanus] usually kept their feet lowered during the approach, even while they 

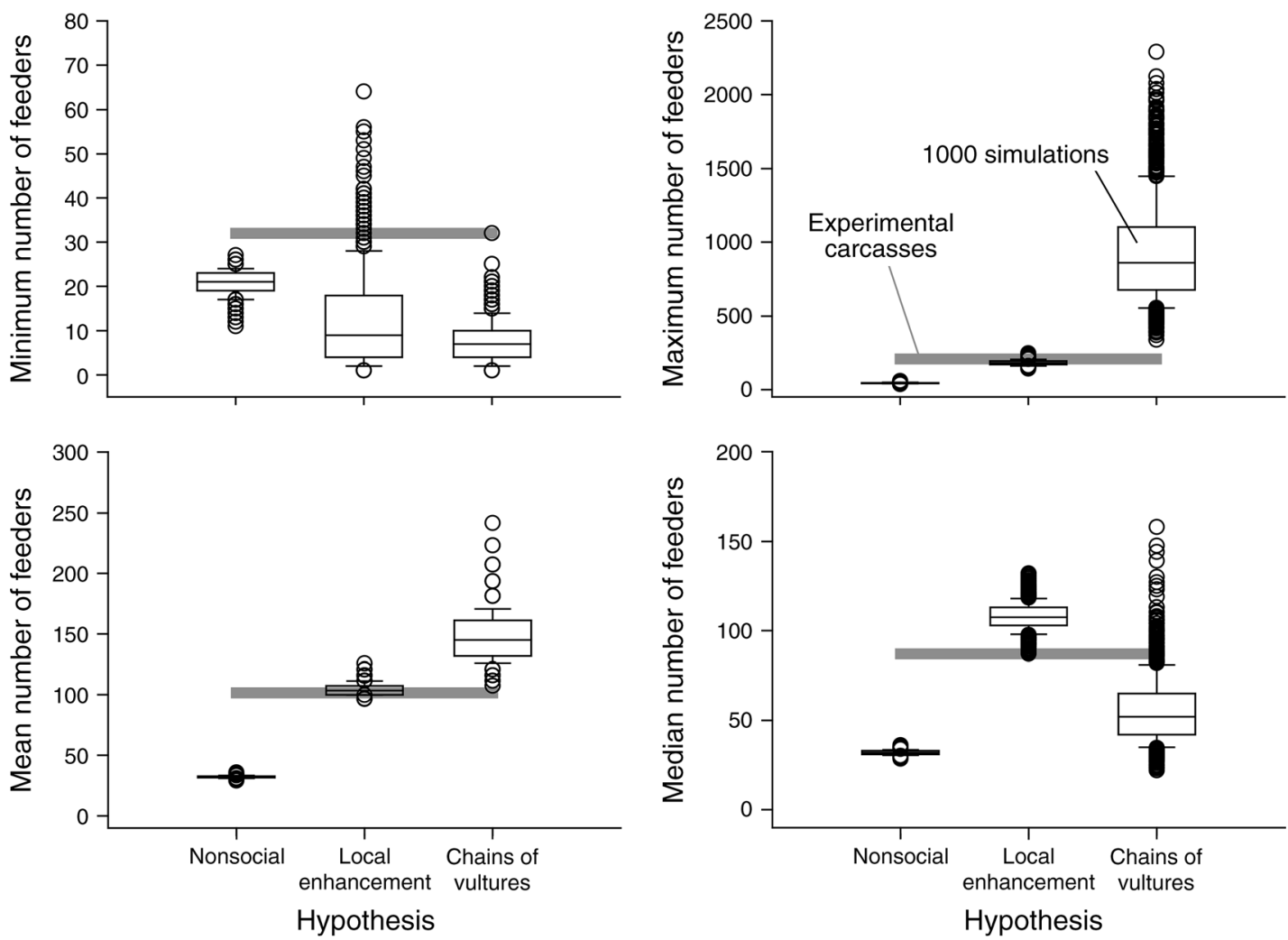

FIG. 4. Boxplots of four metrics characterizing the number of feeders found at each carcass at the end of each model run using default parameterization (Table 2). For instance, for each of the 1000 model runs of each submodel, "maximum" shows the number of feeders attending the carcass with more feeders. The thick gray line shows the value found in experimental carcasses (fieldwork data): minimum (32), maximum (209), mean (101.6), and median (87 feeders). For the boxplots, the lower and upper box boundaries indicate 25 th and 75 th percentiles, respectively. The median is indicated by a line inside the boxes. Lower and upper whiskers indicate the 10th and 90th percentiles, respectively. Dots indicate data outside 10th and 90th percentiles.

were several hundred meters away from their landing site [the carcass]." Thus, it was exceptional that they did so from several hundred meters away, and thus, even less probable that they do so from kilometers away, as needed to create the long chains of vultures that emerge in the simulations (Fig. 2). Moreover, Pennycuick (1972: 190) reports that "When thermals are strong and close together a patrolling vulture may find itself being carried too high, simply as a result of flying straight through a thermal without circling. The usual reaction to this is to lower the feet, which produces extra drag and hence increases the sinking speed (Pennycuick 1971)." Therefore, it seems that the "dropping of the feet" behavior is commonly used by vultures to lose unwanted gained flight altitude (and when sinking to the carcass in the very last moment), rather than to approach to a carcass on a slowly descending flight from several kilometers away.

In any case, our study cannot discard other mechanisms (or a combination of mechanisms) that could be at play. In fact, our results already suggest so, because all three submodels underestimated the minimum number of feeders per carcass. This mismatch can arise from choosing incorrect parameterized values or from structural issues with the model. However, results from the uncertainty analysis suggest that the model output is robust against parameter variation, so more biologically interesting details are likely to cause the differences between model output and field data. For instance, the underestimation of the minimum number of feeders per carcass may suggest that a critical minimum number of vultures circling above the carcass is needed before one vulture decides to descend to the carcass (e.g., vultures may need the continuous cycling of other individuals above the carcass as a way of reinforcing the idea that the place is safe to descend). Alternatively, it may suggest that some other aggregation factor exists for vultures, such as active foraging as a group (Deygout et al. 2010) or communal roosting (Dermody et al. 2011). This would lead to a clumped spatial distribution of foraging vultures, and thus, also a higher minimum number of feeders per carcass. Also, the overestimation of the number of vultures arriving at many simulated carcasses under the chains of vultures suggests that further work is needed to understand if vultures are able to evaluate when it is worth landing at a carcass given 
the amount of food left and the number of vultures already feeding on it. This knowledge will certainly improve future models of this system.

\section{Adaptive function}

It was not the aim of this study to analyze the adaptive nature of the different hypotheses on vulture behavior. However, part of their relative credibility relies on the likelihood of the different hypothesized behaviors to be adaptive with regard to exploiting unpredictable and ephemeral resources. We argue that the local enhancement strategy could be more adaptive than the chains of vultures strategy for two main reasons:

First, social information may be not reliable, leading to a maladaptive informational cascade (Giraldeau et al. 2002), and animals are expected to have adaptations to minimize the costs of unreliable information (Koops 2004). In fact, vultures may be going (or descending) to a carcass, but they may also be going to a pond to drink, to a tree to rest, and so on. This problem is common to the two social hypotheses, but more likely for the chains of vultures. However, the presumed behavior that vultures track from conspecifics under the chains of vultures hypothesis is more subtle, and thus, easier to misinterpret than the direct and fast descending flight of a vulture sinking to a carcass (local enhancement hypothesis). Moreover, the consequences of misinterpreting social cues may be more severe for the chains of vultures strategy because under the local enhancement strategy, a vulture is $<D_{\text {land }}(\sim 7 \mathrm{~km})$ away from the carcass. However, under the chains of vultures strategy, vultures are potentially attracted from much farther away because of the formation of the chain of vultures (Fig. 2).

Second, even if the information is reliable, there is a time-space issue with the use of social information: Its value decreases with time (Seppänen et al. 2007). This is the case for carcasses because they are rapidly depleted (Cortés-Avizanda et al. 2012); i.e., social information may eventually lead to an overcrowded carcass. This is especially true for the chains of vultures scenario, where the model has shown that many vultures can often gather at just a few carcasses (Fig. 3). Specifically, it was common for a single carcass in the model to attract $>209$ vultures, the maximum number found at experimental carcasses. Since all discovered carcasses were completely consumed by vultures within the space of a single day in the field, we are confident in suggesting that, if vultures do follow the chains of vultures behavior, they would often arrive at already depleted carcasses, or at carcasses with elevated intraspecific competition. However, while this could be at play at the study area, this could also differ in other scenarios, e.g., with different vulture or carcass density, or with a different scavenger community. Also, this suggests that, if the chains of vultures strategy is found to occur in nature (e.g., with future studies with GPS loggers), our study suggests that some sort of avoidance of crowded carcasses should be common for the chains of vultures to be an adaptive behavior.

\section{Prospects}

Here we followed Jackson et al. (2008) by assuming an "information-sharing" approach (Clark and Mangel 1984, Ruxton et al. 1995, Beauchamp et al. 1997), where all individuals actively search for carcasses, gathering personal information until they can use social information from conspecifics. It has been suggested, however, that acquiring personal and social information may be incompatible because of cognitive and physical constraints (Giraldeau et al. 2002). This assertion merits further attention because there is some evidence that such a conflict may be at play (Fischer 1969, Pennycuick 1972). Ideally, there is an optimum foraging altitude where the trade-off between the area prospected and the visual acuity maximizes according to prevailing conditions: This would be the expected flying altitude used by vultures using personal information to find carcasses. However, this altitude is likely to be lower than the optimal altitude to gather social information (i.e., observing the flight behavior of conspecifics). This potential trade-off between personal (by flying relatively low) and socially acquired information (by flying relatively high) would lead to a producer-scrounger game scenario (Beauchamp et al. 1997, Giraldeau and Caraco 2000) where individuals either use personal (acting as producers) or socially acquired information (acting as scroungers). A mixture of the "informationsharing" and the "producer-scrounger" extreme scenarios merits further consideration to explain vulture behavior (Beauchamp 2008, Tania et al. 2012).

\section{Conclusions}

Recent theoretical studies aimed at understanding the population consequences of different scenarios for vulture populations have assumed the chains of vultures hypothesis as the only available explanation about how these avian scavengers find carcasses. However, the large number of vultures arriving at many carcasses under the chains of vultures hypothesis clearly does not fit with the data from our field observations (Fig. 3). The local enhancement hypothesis is not only a long-established and plausible alternative, but it is also more parsimonious in its assumption, is potentially more adaptive, and its predictions are more strongly supported by empirical data. This could be important for conservation purposes because these different foraging strategies may predict different population consequences from either vulture or carcass density declines. For instance, under the chains of vultures hypothesis, a concentration of carcasses in a few places could be enough to maintain large-scale vulture populations because individuals would gather from far away. Contrarily, if local enhancement is operating, food concentration could determine harmful effects to the population because 
individuals foraging at distant areas would not recruit. Future modeling studies would be necessary to explore the population consequences of these different "information transfer" hypotheses under divergent ecological and management scenarios.

Our findings highlight the need for further empirical and modeling studies on this fascinating social animal behavior, particularly because our results show that the chains of vultures hypothesis cannot be completely refuted. We suggest that future studies should still consider both hypotheses as competing candidates and take into account further details on avian scavengers' behavior; e.g., vultures may evaluate whether to descend to a carcass according to the number of feeders, vultures often search in groups, and producer/scrounger strategies could co-exist in the population.

As a corollary of our study, we show the relevance of modeling alternative hypotheses about certain key behaviors which can be assumed to strongly affect population-level phenomena. This does not deny the relevance of data-free models to explore the power of individual behavior in creating collective patterns (e.g., Jovani and Grimm 2008, Beauchamp et al. 2012), but highlights the current need for more studies confronting alternative models of key behavioral traits with empirical patterns (Grimm and Railsback 2012) if we want to understand how collective behavior emerges in animal societies (Taborsky 2008).

\section{ACKNOWLEDGMENTS}

We thank M. Carrete, N. Markina, M. Rodriguez, A. Agorreta, D. Campión, M. de la Riva, C. Fernández, M. Razin, and J. I. Deán for their help during fieldwork. E. Avizanda and I. Afán helped with field data transcriptions. A. Jackson and two anonymous referees made helpful comments on earlier versions of the manuscript. This study was partially funded by Viveros y Repoblaciones de Navarra S.A. (Navarre Government) and the project CGL 2009-12753-C02-02. A. CortésAvizanda was supported by a grant from the German Research Foundation (DFG; reference GR 2664/2-1) under the terms of an agreement with the Consejo Superior de Investigaciones Científicas, Spain (CSIC). R. Jovani was supported by a Ramón y Cajal contract (reference 186/2009) by the Spanish Ministry of Science. A. Cortés-Avizanda and R. Jovani contributed equally to the work.

\section{Literature Cited}

Beauchamp, G. 2008. A spatial model of producing and scrounging. Animal Behaviour 76:1935-1942.

Beauchamp, G., P. Alexander, and R. Jovani. 2012. Consistent waves of collective vigilance in groups using public information about predation risk. Behavioral Ecology 23:368-374.

Beauchamp, G., M. Belisle, and L. A. Giraldeau. 1997. Influence of conspecific attraction on the spatial distribution of learning foragers in a patchy habitat. Journal of Animal Ecology 66:671-682.

Burkepile, D. E., J. D. Parker, C. B. Woodson, H. J. Mills, J. Kubanek, P. A. Sobecky, and M. E. Hay. 2006. Chemically mediated competition between microbes and animals: microbes as consumers in food webs. Ecology 87:2821-2831.

Camazine, S., J.-L. Deneubourg, N. R. Franks, J. Sneyd, G. Theraulaz, and E. Bonabeau. 2001. Self-organization in biological systems. Princeton University Press, Princeton, New Jersey, USA.
Clark, C. W., and M. Mangel. 1984. Foraging and flocking strategies: information in an uncertain environment. American Naturalist 123:626-641.

Cortés-Avizanda, A. 2010. The ecological and conservation effects of trophic resource predictability: carcasses and vertebrate communities. Dissertation, Universidad Autónoma de Madrid, Madrid, Spain.

Cortés-Avizanda, A., J. A. Donázar, and M. Carrete. 2010. Managing supplementary feeding for avian scavengers: Guidelines for optimal design using ecological criteria. Biological Conservation 143:1707-1715.

Cortés-Avizanda, A., R. Jovani, J. A. Donázar, and M. Carrete. 2012. Resource unpredictability promotes species diversity and coexistence in an avian scavenger guild: a field experiment. Ecology 93:2570-2579.

Danchin, E., L.-A. Giraldeau, T. J. Valone, and R. H. Wagner. 2004. Public information: from nosy neighbors to cultural evolution. Science 305:487-491.

Del Moral, J. C., and R. Martí. 2001. El Buitre leonado en la Península Ibérica. Monografía number 7. SEO/BirdLife, Madrid, Spain.

Dermody, B. J., C. J. Tanner, and A. L. Jackson. 2011. The evolutionary pathway to obligate scavenging in vultures. PLoS ONE 6:e24635.

De Vault, T. L., O. E. Rhodes, and J. A. Shivik. 2003. Scavenging by vertebrates: behavioral, ecological, and evolutionary perspectives on an important energy transfer pathway in terrestrial ecosystems. Oikos 102:225-234.

Deygout, C., A. Gault, O. Duriez, F. Sarrazin, and C. BessaGomes. 2010. Impact of food predictability on social facilitation by foraging scavengers. Behavioral Ecology 21: $1131-1139$

Deygout, C., A. Gault, F. Sarrazin, and C. Bessa-Gomes. 2009. Modeling the impact of feeding stations on vulture scavenging service efficiency. Ecological Modelling 220:1826-1835.

Donázar, J. A. 1993. Los buitres Ibéricos. Biologia y Conservación, Madrid, Spain.

Donázar, J. A., A. Cortés-Avizanda, and M. Carrete. 2010. Dietary shifts in two vultures after the demise of supplementary feeding stations: consequences of the EU sanitary legislation. European Journal of Wildlife Research 56:613621.

Fischer, V. A. B. 1969. Laboruntersuchungen und Freilandbeobachtungen zum Sehvermögen und Verhalten von Altweltgeiern. Zoologische Jahrbücher/Abteilung für Systematik, Ökologie und Geographie der Tiere 96:81-132.

Galef, B. G., Jr., and L.-A. Giraldeau. 2001. Social influences on foraging in vertebrates: causal mechanisms and adaptive functions. Animal Behaviour 61:3-15.

Giraldeau, L. A., and T. Caraco. 2000. Social foraging theory. Princeton University Press, Princeton, New Jersey, USA.

Giraldeau, L. A., T. J. Valone, and J. J. Templeton. 2002. Potential disadvantages of using socially acquired information. Philosophical Transactions of the Royal Society B 357: $1559-1566$.

Grimm, V., et al. 2006. A standard protocol for describing individual-based and agent-based models. Ecological Modelling 198:115-126.

Grimm, V., U. Berger, D. L. DeAngelis, J. G. Polhill, J. Giske, and S. F. Railsback. 2010. The ODD protocol: a review and first update. Ecological Modelling 221:2760-2768.

Grimm, V., and S. F. Railsback. 2005. Individual-based modeling and ecology. Princeton University Press, Princeton, New Jersey, USA.

Grimm, V., and S. F. Railsback. 2012. Pattern-oriented modelling: a "multiscope" for predictive systems ecology. Philosophical Transactions of the Royal Society London B 367:298-310.

Grimm, V., E. Revilla, U. Berger, F. Jeltsch, W. M. Mooij, S. F. Railsback, H.-H. Thulke, J. Weiner, T. Wiegand, and D. L. DeAngelis. 2005. Pattern-oriented modeling of agent- 
based complex systems: lessons from ecology. Science 310 987-991.

Hertel, F. 1994. Diversity in body size and feeding morphology within past and present vulture assemblages. Ecology 75: 1074-1084.

Hildenbrandt, H., C. Carere, and C. K. Hemelrijk. 2010. Selforganized aerial display of thousands of starlings: a model. Behavioral Ecology 21:1349-1359.

Houston, D. C. 1974. Food searching in griffon vultures African Journal of Zoology 12:63-77.

Jackson, A. L., G. D. Ruxton, and D. C. Houston. 2008. The effect of social facilitation on foraging success in vultures: a modelling study. Biology Letters 4:311-313.

Jovani, R., and V. Grimm. 2008. Breeding synchrony in colonial birds: from local stress to global harmony. Proceedings of the Royal Society B 275:1557-1563.

Karban, R., and J. Maron. 2002. The fitness consequences of interspecific eavesdropping between plants. Ecology 83:12091213.

Koops, M. A. 2004. Reliability and the value of information. Animal Behaviour 67:103-111.

Kruuk, H. 1967. Competition for food between vultures in east Africa. Ardea 55:171-193.

Mundy, P., D. Butchart, J. Ledger, and S. Piper. 1992. The vultures of Africa. Academic Press, San Diego, California, USA.

Ostfeld, R. S., and F. Keesing. 2000. Pulsed resources and community dynamics of consumers in terrestrial ecosystems. Trends in Ecology and Evolution 15:232-237.

Pennycuick, C. J. 1971. Gliding flight of the White-backed vulture Gyps africanus. Journal of Experimental Biology 55: 13-38.

Pennycuick, C. J. 1972. Soaring behaviour and performance of some East African birds observed from a motor-glider. Ibis 114:178-218.

Platt, J. R. 1964. Strong inference. Science 146:347-352.

Railsback, S. F., and V. Grimm. 2012. Agent-based and individual-based modeling. Princeton University Press, Princeton, New Jersey, USA.
Ruxton, G., S. J. Hall, and W. S. C. Gurney. 1995. Attraction toward feeding conspecifics when food patches are exhaustible. American Naturalist 145:653-660.

Ruxton, G. D., and D. C. Houston. 2004. Obligate vertebrate scavengers must be large soaring fliers. Journal of Theoretical Biology 228:431-436.

Schmidt, K. A., S. R. X. Dall, and J. A. van Gils. 2010. The ecology of information: an overview on the ecological significance of making informed decisions. Oikos 119:304316.

Seppänen, J., J. Forsman, M. Monkkonen, and R. L. Thompson. 2007. Social information use is a process across time, space, and ecology, reaching heterospecifics. Ecology 88:1622-1633.

Stamps, J., R. McElreath, and P. Eason. 2005. Alternative models of conspecific attraction in flies and crabs. Behavioral Ecology 16:974-980.

Sumpter, D. J. T. 2010. Collective animal behavior. Princeton University Press, Princeton, New Jersey, USA.

Taborsky, M. 2008. The use of theory in behavioural research. Ethology 114:1-6.

Tania, N., B. Vanderlei, J. L. P. Heath, and L. EdelsteinKeshet. 2012. Role of social interactions in dynamic patterns of resource patches and forager aggregation. Proceedings of the National Academy of Sciences USA 109:11228-11233.

Thorpe, W. H. 1963. Learning and instinct in animals. Methuen, London, UK.

Tristram, H. B. 1867. The natural history of the Bible. Society for Promoting Christian Knowledge (SPCK), London, UK.

Tucker, V. A. 1988. Gliding vultures: descending flight of the white-backed vulture, Gyps africanus. Journal of Experimental Biology 140:325-344.

Valone, T. J., and J. J. Templeton. 2002. Public information for the assessment of quality: a widespread social phenomenon. Philosophical Transactions of the Royal Society B 357:15491557.

Wilensky, U. 1999. NetLogo. Center for Connected Learning and Computer-Based Modeling, Northwestern University, Evanston, Illinois, USA. http://ccl.northwestern.edu/netlogo

\title{
Supplemental Material
}

\author{
Appendix \\ Model description and parameterization details (Ecological Archives E095-159-A1).
}

\section{Supplement}

NetLogo 5.0.3 code used to run individual-based model simulations (Ecological Archives E095-159-A2). 